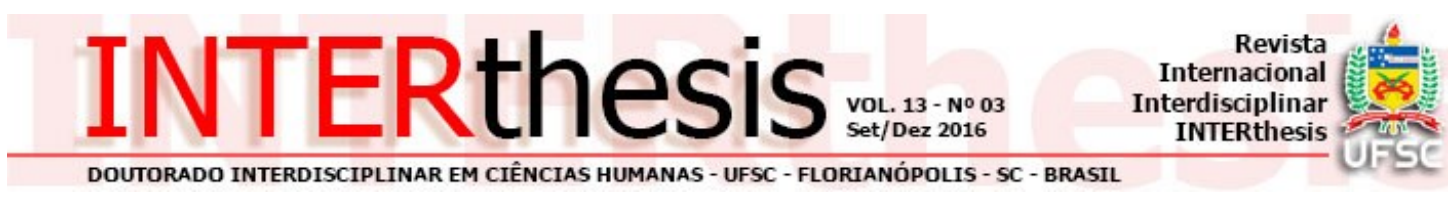

\title{
LIBEREM OS MANGÁS: JUVENTUDES FRENTE À LEITURA E À INFORMAÇÃO
}

\begin{abstract}
Jacira Gil Bernardes ${ }^{1}$
Aline Accorssi ${ }^{2}$

Resumo:

No presente artigo buscamos refletir e discutir os sentidos e significados que jovens de um bairro de periferia possuem acerca da leitura e informação. Para isto, realizamos oito entrevistas semiestruturadas com jovens entre 18 e 24 anos participantes de um projeto social, chamado Casa das Juventudes, no Bairro Guajuviras, de Canoas/RS, Brasil, integrante do Projeto Territórios de Paz. A Casa das Juventudes é um centro de formação e espaço de convivência. Nela funciona o PROTEJO (Proteção de Jovens em Território Vulnerável), projeto social voltado para jovens em situação de violência e outras formas de vulnerabilidade social. Os resultados indicam que a leitura faz parte da vida cotidiana dos jovens, uma vez que os mesmos expressam interesse e iniciativa em ter contato, dentro e fora da Casa, com livros e informações em geral. Contudo, o acesso à leitura é dificultado em seus cotidianos por vários motivos, tais como: ausência de bibliotecas públicas; equipamentos e espaços culturais públicos inadequados, ou por demais suntuosos, em relação à realidade social em que estes jovens estão inseridos. O não acesso à informação configura-se mais pela falta de acervo adequado nas bibliotecas, associado ao alto custo para a aquisição de livros e outros documentos, do que a falta de interesse pela prática da leitura.
\end{abstract}

Palavras-chave: Leitura. Juventude. Equipamento cultural. Biblioteca.

\section{INTRODUÇÃO}

É a partir da observação do mundo, do nosso cotidiano e de nossas experiências, que surge o interesse e, também, a urgência de refletir sobre a prática de leitura e os processos educativos, especificamente em comunidades reconhecidas socialmente como "populares" ou de "baixa renda".

No atual momento em que vivemos, de constantes transformações tecnológicas e informacionais, muito se discute sobre leitura, Internet, novos suportes dos documentos e a constante ameaça do término dos livros impressos.

\footnotetext{
${ }^{1}$ Mestre em Memória Social e Bens Culturais, pelo Centro Universitário La Salle, Canoas, RS, Brasil E-mail: jaciragb@ufrgs.br

2 Doutora em Psicologia pela Pontifícia Universidade Católica do Rio Grande do Sul com estágio na Escola de Altos Estudos em Ciências Sociais de Paris. Professora nos Cursos de Psicologia e Pedagogia e professora-pesquisadora no Programa de Pós-Graduação em Memória Social e Bens Culturais do Centro Universitário La Salle, Canoas, RS, Brasil. E-mail: alineaccorssi@gmail.com
} 
Estar "sempre acessível e conectado", segundo Dupas (2007), é quase uma obrigação e nos sentimos culpados quando assim não procedemos. Neste sentido, mesmo que a "revolução digital" tenha mudado a forma como nos relacionamos e/ou acessamos a informação, é preciso reconhecer que grande parcela da população brasileira ainda se encontra à margem das novas tecnologias e à margem do acesso à informação. Sem poder adquirir equipamentos eletrônicos, livros, revistas e jornais, os grupos socioeconômicos desfavorecidos podem recorrer a espaços públicos como bibliotecas, casas de cultura ou outros locais disponíveis para a sua inserção cultural. Mas não é o que acontece.

Não é fácil ter acesso à leitura, aos livros e à informação: de um modo geral bibliotecas escolares são deficitárias, acervo escasso, sem estrutura física, quando existem. Bibliotecas públicas se apresentam de forma inacessível, seja pela localização, longe da periferia e/ou suntuosas, o que afasta e assusta muitas pessoas ou pela sua inexistência. Quando existe um espaço de leitura, a população não o utiliza, não se apropria daquele local porque possivelmente não é adequado a sua realidade, não é adaptada ao seu dia a dia, não é moderno e "inovado" o suficiente.

Frente às novas necessidades do mundo contemporâneo, como podemos compreender o papel da leitura, das bibliotecas e, até mesmo, daqueles que nelas trabalham? A realidade em que estão inseridas envolve não somente novas tecnologias, mas também novas formas de oferecimento do acesso, novos espaços de leitura, a busca ao usuário ausente, através da promoção da leitura, e uma nova visão social de seus papéis. Além disso, um espaço de leitura e acesso a informação será o mesmo independentemente da idade e interesses dos usuários? Pensamos que não. Precisamos conhecer as demandas daqueles que já acessam as bibliotecas, bem como dos usuários potenciais, a fim de possibilitar experiências significativas no campo educacional.

Nosso objetivo, portanto, é refletir e discutir os sentidos e significados da leitura e da informação de jovens residentes de uma comunidade periférica da cidade de Canoas/RS. Consideramos a temática relevante, pois, a partir de nossa experiência, notamos que é necessário muito mais do que simplesmente entregar um livro a um usuário de biblioteca ou disponibilizar uma informação nas mídias. É preciso a tomada de consciência, não só por parte dos usuários, mas de todos os cidadãos, de seus direitos e a inclusão informacional como forma de luta pela R. Inter. Interdisc. INTERthesis, Florianópolis, v.13, n.3, p.81-100 Set.-Dez. 2016 
igualdade, proporcionando meios que permitam ao ser humano seu pleno desenvolvimento de forma a possibilitar sua intervenção enquanto cidadãos no contexto social em que vivem. Assim, nos próximos itens abordamos alguns dados relevantes em torno do acesso à leitura e à informação no Brasil e, logo após, algumas reflexões sobre o conceito de juventude.

\section{ACESSO À LEITURA E À INFORMAÇÃO}

Inicialmente é preciso atualizar dados que tratam sobre a questão da leitura no Brasil. Na pesquisa realizada pelo Instituto Pró-Livro (2011), sobre os Retratos da Leitura no Brasil, que teve como objetivo "Medir intensidade, forma, motivação e condições de leitura da população brasileira", verifica-se que o brasileiro leu, em média, 1,85 livro nos últimos três meses. Esta média, ainda que possa parecer alta, significa que os brasileiros não leem um livro por mês. É mais baixa comparando com a pesquisa de 2007, que apontava uma média de 2,4 livros nos últimos três meses. Nessa mesma publicação, é indicado que $67 \%$ da população pesquisada sabem da existência de uma biblioteca pública na sua cidade ou no seu bairro e $71 \%$ consideram de fácil acesso, mas, ao mesmo tempo, $75 \%$ não frequentam a biblioteca, $7 \%$ usam frequentemente e 17\% usam de vez em quando. Constatamos então, que a população sabe da existência das bibliotecas, mas não as utilizam. Com base nessas informações podemos dizer que a formação de uma nova geração de leitores só será possível com novas intervenções, tanto de educadores quanto dos governos na construção de estratégias que democratizem o acesso à leitura no Brasil.

O Primeiro Censo Nacional das Bibliotecas Públicas Municipais (2011), realizado no ano de 2009 , indica que $79 \%$ dos municípios brasileiros possuem ao menos uma biblioteca aberta, o que corresponde no país a 2,67 bibliotecas por 100 mil habitantes, valor este muito abaixo do necessário. Dessas bibliotecas existentes, somente $27 \%$ oferecem acesso à internet, o que consiste um atraso. Afinal, com todos os recursos e informações disponíveis na web nos dias atuais, não dispor de acesso à mesma pode ser um fator de afastamento de jovens usuários dos locais de leitura.

De acordo com a UNESCO, o acesso à cultura no Brasil é desigual, pois no que se refere ao acesso aos Livros e Bibliotecas:

R. Inter. Interdisc. INTERthesis, Florianópolis, v.13, n.3, p.81-100 Set.-Dez. 2016 
[...] o brasileiro praticamente não tem o hábito de leitura. A maioria dos livros estão [sic] concentrados nas mãos de muito poucos. O preço médio do livro de leitura é muito elevado quando se compara com a renda do brasileiro nas classes C/D/E. (UNESCO, 2011, p.1)

Frente a tal realidade, o governo federal, por meio de políticas públicas, tenta resolver o problema da falta de leitura. Dentre as políticas públicas do Brasil, foi criado o Plano Nacional do Livro e Leitura (PNLL), que é "um conjunto de projetos, programas, atividades e eventos na área do livro, leitura, literatura e bibliotecas em desenvolvimento no país, empreendidos pelo Estado [...]" (PLANO NACIONAL DO LIVRO E LEITURA, 2011, p.1). Muito embora algumas dessas iniciativas já tenham sido realizadas, pensamos que ainda é pouco, não refletindo, na sua totalidade, no dia a dia do brasileiro.

\section{JUVENTUDE X JUVENTUDES}

A bibliografia especializada em juventude(s) e documentos relativos a políticas públicas para esta faixa populacional, tem definido duas formas de caracterizar este termo: no singular e no plural. Velho e Duarte $(2010$, p. 7) assinalam que, neste caso, "O plural salienta a complexidade da sociedade moderno-contemporânea, ao mesmo tempo que busca evitar uma simplificação e um empobrecimento das importantes diferenças encontradas e analisadas". Da mesma maneira, a UNESCO (2004, p. 25), ao falar de políticas para a juventude, considera a multiplicidade das culturas juvenis, destacando o plural da palavra juventudes.

Ainda que haja um conjunto de influências sociais compondo a subjetividade dos jovens, sabemos que não existe um padrão uniforme que possa caracterizar tal grupo. "É nesse sentido que enfatizamos a noção de juventudes, no plural, para enfatizar a diversidade de modos de ser jovem existentes" (DAYRELI, 2003, p. 42)

As juventudes hoje são influenciadas pela rapidez do mundo moderno, a comunicação online, as relações traduzidas com o "ficar", fenômeno quase sempre passageiro, as interações são todas ao mesmo tempo: pessoais, celular, som, computador, televisão e têm disposição para ficarem conectados 24 horas e estarem em várias redes sociais. Estão disponíveis para, facilmente estabelecerem relacionamentos sociais a distância. Os jovens estão constantemente fazendo escolhas que lhes são próprias e que mudam a cada dia. A linguagem é 
diferenciada, agrupam-se e se reagrupam constantemente. Nesta "vida líquida", conforme Bauman (2007, p. 7), em que tudo é rápido e passageiro com os jovens não poderá ser diferente numa "[...] sociedade em que as condições sob as quais agem seus membros mudam num tempo mais curto do que aquele necessário para a consolidação, em hábitos e rotinas, das formas de agir".

Conforme Galvão (2008, p.1) "As transformações sociais alteraram o modo pelo qual os jovens se colocam diante do mundo", impactando, portanto, a questão identitária.

[....] Dentro desse quadro, manifesta-se uma nova configuração de identidade que busca referências geograficamente distantes, mas próximas em interesses. Mesmo o hip hop, identidade cultural principalmente de jovens moradores de periferia, foi inserido numa rede de comunicação de massa que atua como uma nova referência para a construção de uma identidade global e inter-territorial. (GALVÃO, 2008, p.1)

Muitos jovens, por sua condição socioeconômica, como outros grupos no Brasil, têm dificuldades de acessar a cultura, o lazer, e outras formas de sociabilidade. Formam novas turmas ou se inserem nos grupos já existentes. Esta formação ou inserção em grupos já formados é uma opção "barata", acessível, trazendo resultados imediatos. Sposito (2006, p. 100) nos diz que "[...] é preciso considerar que o momento da juventude é rico em manifestação da sociabilidade $[\ldots]$..

Já Catani e Gilioli (2008) ressaltam a procura das juventudes por espaços públicos de lazer.

Se observarmos que os jovens de condições sociais modestas quase não têm espaços públicos que os acolham ou Ihes ofereçam oportunidades, as gangues e as outras "tribos" urbanas podem ser consideradas espaços organizados de socialização que os habilitam para a sobrevivência em um ambiente social hostil e constituem um referencial para lidar com as instituições tradicionais (escola, família, etc.). (CATANI; GILIOLI 2008, p. 101)

Em seu tempo livre, "[...] os jovens constroem suas próprias normas, expressões culturais, ritos, simbologia e modos de ser que os diferenciam do denominado mundo adulto" (BRENNER; DAYRELL; CARRANO, 2005, p.176). E muitos jovens utilizam o seu tempo livre dedicando-se a música. A música é um produto cultural consumido pelos jovens.

A música acompanha os jovens em grande parte das situações no decorrer da vida cotidiana: música como fundo, música como linguagem comunicativa que dialoga com outros tipos de linguagem, música como estilo expressivo e artístico; são múltiplas as dimensões e os significados 
que convivem no âmbito da vida interior e das relações sociais dos jovens, sendo mais vivida do que apenas escutada. (DAYRELL, 2001, p.21)

Tais considerações, portanto, não podem ser simplesmente desconsideradas quando pensamos em espaços democráticos de acesso à leitura e informação com jovens. Passamos agora, para algumas considerações metodológicas, referente ao desenvolvimento do estudo.

\section{METODOLOGIA}

\subsection{Produção de informações}

Para a produção das informações, realizamos entrevistas individuais, do tipo semiestruturadas que, conforme Minayo (2007, p. 267), "obedece a um roteiro que é apropriado fisicamente e utilizado pelo pesquisador". Todas as entrevistas foram transcritas e sistematizadas a partir de uma análise de conteúdo temática (MINAYO, 2011) visando o processo interpretativo.

\subsection{Sujeitos e o contexto da pesquisa}

Entrevistamos jovens entre 18 e 24 anos, participantes da Casa das Juventudes, no Bairro Guajuviras, em Canoas/RS. A Casa das Juventudes é uma iniciativa integrante do Projeto Territórios de Paz. Configura-se por ser um centro de formação e espaço de convivência, onde funciona o PROTEJO (Proteção de Jovens em Território Vulnerável), destinado a jovens em situação de violência e outras formas de vulnerabilidade social.

Tivemos o cuidado de explicitar e esclarecer aos participantes os objetivos da pesquisa, bem como a qualidade voluntária de sua participação. Além disso, é importante destacar que o estudo fez uso de Termos de Consentimento Livre e Esclarecido, o qual foi assinado pelos participantes que optaram em colaborar com o estudo.

\subsection{Análise das informações}

Os dados ou informações provenientes das entrevistas foram organizados e sistematizados a partir de categorias temáticas (MINAYO, 2011). Tais categorias emergiram do conteúdo das entrevistas, apresentando relação com o objetivo do 
presente estudo. São elas: Compreensão sobre o ato de ler; A experiência da leitura; Os interesses e gostos; e Acesso à leitura.

Ao buscar sustentação para analisar e interpretar as formas como os jovens percebem os sentidos e significados sobre a prática de leitura e a democratização do acesso à leitura e à informação, recorremos a Ferreira e Dias (2004) para a conceitualização:

Sentido e significado têm sido tomados como termos diferenciados, mas relacionados. Sentido tem sido concebido como algo pertencente ao universo pessoal do indivíduo, mas compartilhado dentro do contexto de interação; enquanto significado tem sido compreendido como algo culturalmente compartilhado. (FERREIRA; DIAS, 2004, p. 440)

Para subsidiar a apresentação e interpretação dos dados foram utilizados alguns trechos das entrevistas, procurando dar conta da totalidade e complexidade das falas.

\section{ANÁLISE E DISCUSSÃO DAS INFORMAÇÕES}

\subsection{Compreensão sobre o ato de ler}

As informações contidas nesta categoria ressaltam alguns discursos que apresentam importantes características sobre a forma como os jovens pensam a leitura. Quando expressam a sua compreensão sobre o tema, relatam especialmente em suas atividades cotidianas, isto é, na escola, em família, e em casa. Em sua grande maioria relacionaram leitura com o livro impresso, com responsabilidade, com compromisso, isto é, com situações voltadas à escola que associa leitura como obrigação. O aluno tem que ler um livro para fazer uma prova, um seminário, um trabalho.

Decorrente disto, dois jovens associam 'preguiça' quando pensam em leitura, relacionando com "falta de vontade de ler" e novamente com o que é obrigatório. Não estaria a escola afastando o aluno da leitura com a obrigatoriedade de leitura associada ao compromisso e não ao lazer? Cada obra lida necessariamente resulta em um "trabalhinho". Além deste fator, a lista de obras não é sugerida pelos alunos e sim imposta a eles. Está desassociada da realidade das juventudes, de seus interesses, não estimulando a vontade de ler. Areias reflete sobre esta questão:

[...] a escola termina por desenvolver desde as séries iniciais a prática da leitura como algo mecânico e exaustivo. Ao desconsiderar que o seu

R. Inter. Interdisc. INTERthesis, Florianópolis, v.13, n.3, p.81-100 Set.-Dez. 2016 
educando traz consigo histórias e experiências de vida, ela não possibilita outras formas de leitura, outros espaços de desenvolvimento literário, criando e legitimando. (AREIAS, 2008, p. 4)

Quando questionados sobre o que lembra a palavra leitura, três jovens em suas respostas incluíram a palavra 'livro', reforçando o tema anterior, e outros dois lembram do livro impresso, seja ouvindo histórias ou através de um autor:

O que lembro mesmo é meu pai contando histórias bem sinceramente é
exatamente isto, lembro do meu pai sentado na cama, né, sempre desde pequeno,
contando umas histórias, é isso, leitura, um outro mundo que se abre na mente,
acho muito bacana lê. (l., 18 anos); 'Leitura é mais conhecimento, pra mim leitura
é, por exemplo, Castro Alves, descobre várias coisas interessantes, é saber
bem mais, ser menos burro, isto é que eu acho interessante na leitura. (J.,
18 anos)

Observamos que, alguns dos entrevistados ao falarem sobre a leitura, indicam que não leem, mas na continuidade da sua entrevista percebemos a associação que fazem da leitura com o livro impresso. Chartier (apud Carvalho, 2012, p. 41) indica que o importante é o texto e não o seu formato ao dizer: "Os autores não escrevem livros: não, eles escrevem textos que se tornam objetos escritos, manuscritos, gravados, impressos e, hoje, informatizados". Os jovens ao indicarem que leem na Internet, colocam como exemplos a leitura de jornais, revistas, blogs. Desta maneira, não relacionam textos em outros suportes com o ato de ler. Oswald e Rocha (2013, p. 269) falam sobre a invisibilidade das práticas de leitura dos jovens quando dizem que

[...] é o do estreitamento daquilo que se define como leitura, limitada ao livro impresso, valorizando-se apenas a leitura literária. Outros gêneros e suportes de leitura permanecem excluídos. Tais desdobramentos produzem a invisibilidade das práticas de leitura de segmentos juvenis, desconhecendo suas particularidades e retirando-lhes a legitimidade. (OSWALD; ROCHA, 2013, p. 269)

Os significados construídos pelos entrevistados sugerem que eles reconhecem e valorizam a leitura não só porque esta melhora o conhecimento, mas também pelo incentivo à aprendizagem que oferece. Está associada a algo "positivo", que traz benefícios ao sujeito.

\subsection{A experiência da leitura}

Nesta categoria, percebemos claramente nas entrevistas os sentidos que os jovens dão para a leitura. Alguns aspectos centrais nas falas indicam a constante busca pelo esquecimento de sua própria realidade. Um tipo de fuga da realidade, caracterizado pela preferência de leitura de literatura estrangeira, com preferência a temáticas como mitologia e cultura de outros países. São temas que apresentam

R. Inter. Interdisc. INTERthesis, Florianópolis, v.13, n.3, p.81-100 Set.-Dez. 2016 
fracos laços com a realidade brasileira, ou mesmo poesia, evitando contato, através da leitura, com o seu cotidiano. Em relação a este aspecto, podemos nos inspirar nas reflexões de Carvalho (2012, p. 49) que diz que, ao ler um texto com uma "história fantástica, romântica, ficcional", o leitor pode se transportar para a história lida, tornando-se um coautor, podendo interferir nele, dando um significado a partir de suas próprias experiências.

Tal significado pode ser visto quando os jovens associam a experiência da leitura a uma espécie de 'terapia', de 'refúgio'. Mesmo não usando o termo terapia um jovem fala neste sentido ao dizer:

Pra mim eu sinto assim, eu sinto uma... eu sinto que leitura pra mim é meio uma terapia porque às vezes eu tô nervosa, ah brigou com o namorado, brigou com a mãe, não sei que, eu tô lendo lá um livro e daí eu fico viajando, daí eu esqueço sabe, mas um problema assim, que eu acho que é um baita de um defeito meu é que se eu leio um romance eu fico idealizando se meu namorado vai ser que nem o cara do livro, então é uma coisa assim que eu tenho que mudar porque às vezes eu fico pensando e uma vez até falei pra ele, tá que ele também tinha lido o livro: Tu não viu que ele falou isto pra guria porque tu não pode falar pra mim, sabe, eu fico meio viajando. Não se ela foi eu também posso ser. Basicamente eu penso que é uma terapia pra mim.(F., 18 anos).

É, desfocar, né, vamos dizer assim, é entrar num mundo onde tu foge da sociedade, entendeu, alguns fazem isto escutando música, outros fazem isto vendo filme, outros fazem isto lendo, fogem da realidade entendeu, tu por exemplo, trabalha o dia inteiro, ai tu quer chegar em casa ah não aguento mais isto só televisão, só tragédia, só coisa, tu pega um livro e vai lê, por exemplo, entendeu, tu pega lá, pá olha só, tô num outro mundo, por exemplo, eu tô no espaço, lá histórias de... biografia. (M., 18 anos).

Em sentido semelhante, dois jovens usaram as palavras 'viagem e 'viajar'.

Eu gosto de me concentrar porque normalmente eu imagino as vozes das pessoas, é, eu viajo assim completamente, eu imagino o cenário, imagino como a pessoa é, porque este último livro que eu li, ele é muito, muito descritivo, sabe, e ele fala assim todas as características possíveis dos personagens então eu imagino como seja, eu imagino como seja a voz das pessoas e se no livro tem algum nome de uma pessoa que eu conheço eu meio que fico associando a pessoa sabe, eu dô uma viajada dessas, às vezes.(F., 18 anos );

[...] mas a leitura é flutuar, é uma história tá lendo aqui e já tá pensando lá, bah, como é que foi, como é que é. A Guerra dos Farrapos já tá pensando pá, muito cavalo, muita espada, muita guerra, fogo, tiro, a imaginação já tá lá, a imaginação já tá lá. Viaja através dos livros, é isto que eu entendo leitura. (S., 22 anos)

Com relação à utilização da leitura como terapia, Caldin (2001, p. 1) aponta que "A função terapêutica da leitura admite a possibilidade de a literatura proporcionar a pacificação das emoções". Da mesma forma, um jovem coloca:

Ah, eu acho que eu fico assim fora da casinha porque, meu Deus, eu fico, como é que vou te explicar, que nem te falei, eu imagino tudo, eu imagino as vozes, eu imagino as cenas, eu imagino também tinha uma cena que dizia que 2 jovens de

R. Inter. Interdisc. INTERthesis, Florianópolis, v.13, n.3, p.81-100 Set.-Dez. 2016 
uma família brigavam com 2 crianças, no caso, de uma família brigavam com 2 crianças de outra familia, por causa de um boné de beisebol, eu imaginava daí dizia "as duas crianças chegaram na cerca da família" tá e eu imaginava a cerca. (F., 18 anos)

A tentativa de fugir da realidade através da leitura é reforçada por Marina e Válgoma (2007) quando falam no efeito "salvador" do livro. "Só quem leu fugindo de qualquer coisa pode entender o livro como um doce refúgio, um lugar onde nunca seremos incomodados. A nossa desejada solidão povoada apenas por vozes e personagens" (MARINA; VÁLGOMA, 2007, p. 131). A experiência da leitura nada mais é que "[...] dar um sentido de conjunto, uma globalização e uma articulação aos sentidos produzidos pelas sequências". Isto não significa que o sentido criado pelo autor deva ser o mesmo encontrado pelo leitor. Aliás, uma coincidência entre o sentido desejado e o sentido percebido, requer, entre outros fatores, um acordo cultural entre ambos, o que nem sempre é possível. "[...] Ler é, portanto, constituir e não reconstituir um sentido" (GOULEMOT, 1996, p. 108). E é justamente neste exercício, de constituição de novos sentidos, que os jovens desenvolvem sua imaginação e criatividade.

\subsection{Os interesses e gostos}

Como já havíamos demonstrado anteriormente, há uma insatisfação, por parte dos jovens, com o que é imposto pelas escolas, no que se refere a escolha de leitura. Os jovens nos explicam:

A minha opinião sobre livros obrigatórios é que todos são ruins [...] assim, muito história ruim, do cara que sofria pela mulher, e que fez tudo por ela, e acaba abandonando ele, literatura brasileira, romantismo, barroco, não é o meu forte. (M., 18 anos);

Ah, eu não vou negar porque mesmo eu gostando de ler, tem livros que eles falam eu penso assim ah, não quero, sabe, eu penso principalmente literatura mais puxada assim, não por preconceito mas aquelas literaturas indígenas que falam muito dos índios e do nordeste e do quanto sofreu. (F., 18 anos);

Ah, eu procuro ler de tudo assim, mas não, ahm, que nem Machado de Assis, essas coisas assim, eu não gosto, sabe, fica mais....acho que não procuro lê isto, procuro, às vezes eu nem vejo o escritor, eu só vou lendo assim, o, como é que vou dizer assim, a capa sabe, daí se eu gostar eu vou abrindo, vou abrindo, leio ali, vou lendo até o resumo pra ver o jeito que é, daí eu vou, conforme pego o livro e vou lendo, eu vou lendo, ai gostei vou lá e pego outro e assim vai. (L., 18 anos).

Concordamos com Areias (2008, p. 8) ao afirmar que "enquanto não forem aproveitadas as práticas de leituras juvenis presente em seu cotidiano, vai se 
difundindo a idéia [sic] de que jovem não gosta de livros e não se interessa pela leitura”.

Na figura 1 comparamos a preferência dos jovens com relação à leitura por lazer/prazer e a leitura imposta pela escola, por obrigação.

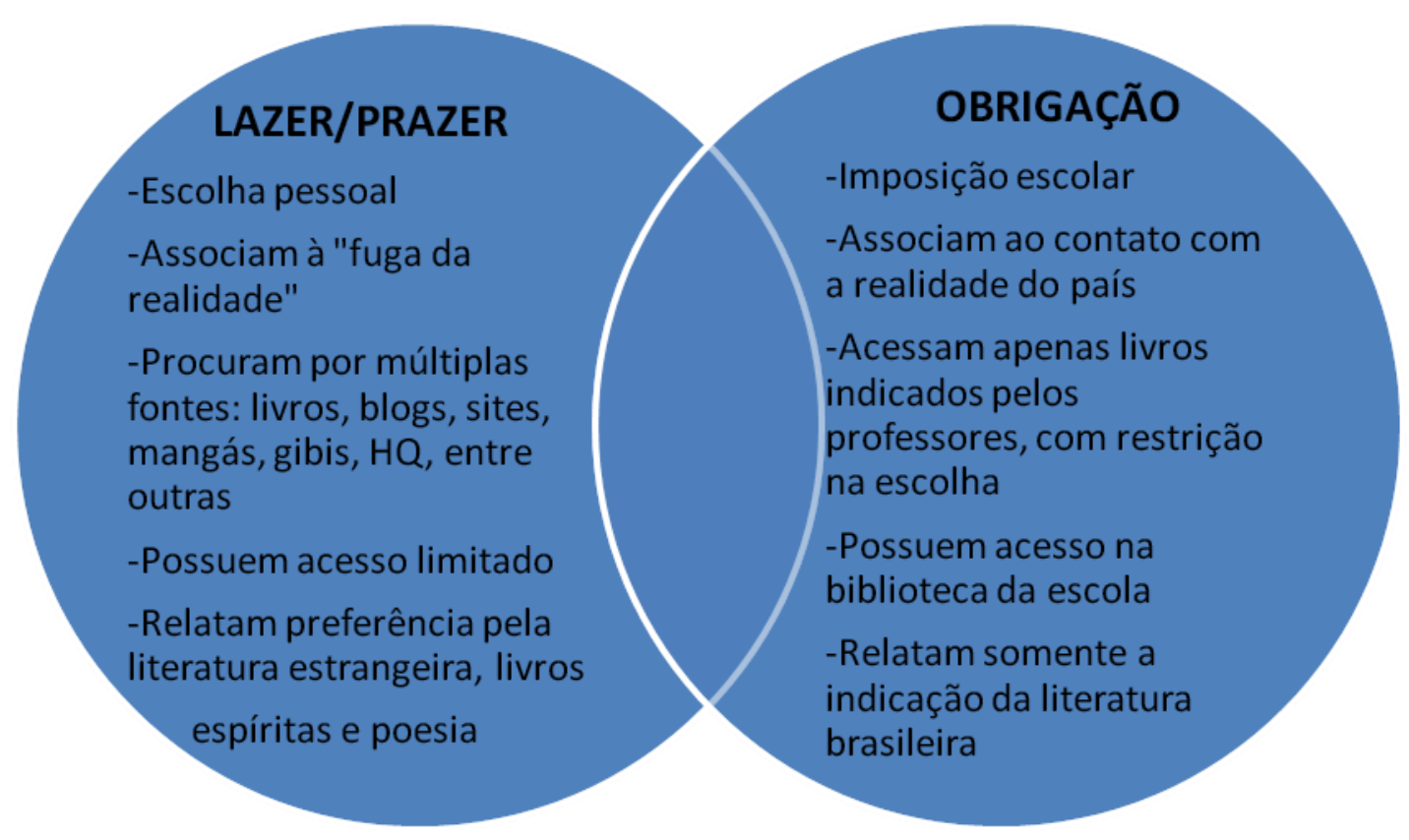

Figura 1 - Preferência dos jovens.

Fonte: Jacira Gil Bernardes (2013)

A ideia do que atrai os jovens para a leitura, que vem ao encontro dos resultados da nossa pesquisa, é colocada por Areias (2008):

Dessa forma, não parece razoável dizer que a juventude se encontra indiferente à leitura. Antes de se programar campanhas para aquisição de livros, é preciso refletir a quem se deseja alcançar. De fato, os jovens não lêem ou apenas não Ihes atraem as leituras valorizadas pela sociedade / escola? (AREIAS, 2008, p.8)

Com relação à leitura preferida dos jovens percebemos o interesse pela cultura de outros países. Isto pôde ser visto, em especial, através da procura e interesse por materiais sobre o Japão, com a participação nos eventos de animês ${ }^{3}$ e leitura de mangás ${ }^{4}$, como demonstra a seguinte fala:

Eu leio mangás na Internet porque o Brasil não produz nenhum tipo de mangá atualizado, por exemplo, Naruto, Naruto tá no mangá volume 42 aqui no Brasil, lançando de dois em dois meses, no Japão a cada 3 meses eles lançam um, tá no volume 87, olha a atualidade disto. (M., 18 anos).

Animês - Desenhos animados japoneses

Mangás - Histórias de quadrinhos japoneses

R. Inter. Interdisc. INTERthesis, Florianópolis, v.13, n.3, p.81-100 Set.-Dez. 2016 
Ao final da entrevista de um jovem, perguntamos se ele gostaria de dizer mais alguma coisa, ao qual respondeu que sim. Disse apenas uma frase representando tanto sua preocupação quanto ao acesso atualizado de mangás no Brasil, quanto a possibilidade de ser autônomo na escolha de suas leituras: 'Liberem os mangás' (M., 18 anos).

Os eventos de animês, hoje já ocorrendo em diversas cidades do Brasil, apresentam uma série de atividades, desde músicas cantadas em japonês, venda de material e concurso de cosplay5. "Por sua grandiosidade (por vezes, atrai mais de 30 mil frequentadores), funcionam como vitrine desse universo, atraindo novos aficionados, geralmente levados por algum colega otaku6." (LOURENÇO, 2010, p. 71). Nesses eventos, ainda segundo o mesmo autor, os jovens encontram-se para divertir-se e "[...] há a possibilidade de mostrar-se como um indivíduo singular, adepto de um gosto que foge dos padrões tradicionais [...]". Animês e mangás atraem o interesse de jovens do Brasil (LOURENÇO, 2010). Contudo, "Se o jovem não está habituado a ler um clássico da Literatura Brasileira, mas sim, mangás, por exemplo, é comum essa prática não ser valorizada socialmente." (AREIAS, 2008, p. 1).

Outro aspecto interessante, é que nas entrevistas os jovens se referiram à área musical de modo singular. Dayrell (2001) diz que a música é a atividade que costuma os envolver e mobilizar. Muitos jovens deixam de "ser simples fruidores da música e passam também a ser produtores, formando grupos musicais [...], compondo músicas e letras, apresentando-se em festas e eventos, criando novas formas de mobilizar os recursos culturais da sociedade atual além da lógica estreita do mercado" (DAYRELL, 2001, p. 4).

A presença da música se manifesta de várias maneiras e também se relaciona com a leitura:

Ontem eu estava lendo um, como que é, aquelas aqueles livrinhos de...que ensina a tocar ...tocar violão [...] No comecinho eu e os guri se criemo fazê um grupo, né, até cheguemo a se apresentar só que não deu muito certo, né, eu era baterista, este meu amigo ai que era muita faixa meu era o vocalista, né, nós fizemo um rap, né, que o esquema que te falei que alertava a juventude sobre faz isso falava do bairro né, a música foi...foi o nome dela foi Liberdade no Guaju, só que já desmanchamo, né. (S., 22 anos);

Cosplay - Jovens vestidos de personagens de mangás e animês

Otaku - fãs de animês e mangás

R. Inter. Interdisc. INTERthesis, Florianópolis, v.13, n.3, p.81-100 Set.-Dez. 2016 
'[...] e ponho o celular assim mais ou menos baixinho, baixinho, só pra me concentrar e deixo uma música não agitada, assim, fico bem tranquilo pra lê.' (J., 18 anos);

Eu tô mais envolvido com o lado do hip hop. Hip hop que é legal e envolve todos os ritmos. Quando eu vi o hip hop de verdade bah, eu fiquei curioso, assim, bah, será que eu podia? Até sonhei e bah [...] E hoje tá, pouco a pouco tá se tornando realidade. Já tenho as minhas composições que é totalmente diferente, eu sempre tento fazer um diferencial não vou pelo o que os outros fazem. E eu quero pouco a pouco trabalhar ainda mais agora que eu... que eu conheci outro grupo, na verdade Força Jovem Brasil' (Fa., 19 anos); 'Agora falaram que eu tinha que escrever música eu boto no meu nome, mas às vezes eu não coloco. (D., 21 anos)

Os jovens demonstram escrever de diversas maneiras: letras de músicas, pensamentos e histórias. Carvalho (2012) reconhece que os jovens escrevem, mas não nos padrões convencionais.

\begin{abstract}
Escrevendo suas narrativas ficcionais ou apenas postando comentários em blogs acessados e lidos por jovens, identificam-se com a temática ou, ainda, configurando seus perfis nas redes sociais, esses sujeitos expõem-se, mostram-se. Escrevem sobre o que amam, o que odeiam, falam de sonhos, desejos, realizações, buscas pessoais, em um ambiente não legitimado pelas instituições e também por alguns grupos sociais. A partir dessas vivências, podem tornar-se blogueiros renomados, escritores conhecidos, twiteiros muito seguidos, ficwriters com muitos leitores. Exercem um lugar autoral que, hoje, já podemos dizer não se tratar apenas de um passatempo da fase juvenil. (CARVALHO, 2012, p.17)
\end{abstract}

Contudo, também é frequente a desvalorização da sua própria escrita quando indicam descartar o material produzido, tal como coloca o jovem:

De vez em quando sim, quando às vezes quando eu tô sem nada pra fazer assim, escrevo umas coisas, mas tento escrever umas músicas falando algumas coisas [...]. É solto, assim, meio idiota, meio idiota as coisas minhas assim. Aham, escrevo num papel, num papel, depois me desfaço. (Lu., 18 anos).

Em um tempo de publicização do eu (SANTOS; DE MARCO, 2012), vemos aqui um movimento contrário, o desprezar das produções ao invés de compartilhar com seus pares. Tal movimento pode ser compreendido dentro de um contexto maior, investigado, por exemplo, por Castro e Abramovay (2002), que aborda a problemática da baixa autoestima entre jovens, em especial os que vivem na periferia das grandes cidades, fruto de múltiplas discriminações.

\title{
5.4 Acesso à leitura
}

Essa categoria evidencia que o acesso à leitura e à informação se configura em um velho e persistente problema. Ao falarem como acessam os livros, os jovens indicaram a compra de livros, revistas e outros materiais de interesse. Tais dados 
mostram a importância que esses jovens dão à leitura e à informação embora tenham o acesso dificultado. Constatamos que existe uma grande carência de informação por parte dos jovens de materiais de seu interesse. A única forma de acesso público à leitura e à informação é a biblioteca da escola, que não apresenta em seu acervo material que os jovens gostariam de ler. A compra de material, livros ou revistas, foi caracterizada por três jovens, demonstrando o grande interesse por informação.

Oswald e Rocha (2013, p. 273-274) dizem que:

Assistimos, assim, a um verdadeiro paradoxo, pois se no ambiente escolar os professores reclamam que os alunos não querem ler e muito menos escrever, fora da escola, o acesso à internet em casa, ou via dispositivos móveis (telefones celulares, redes $3 G$, wi-fi),estimula crianças e jovens não só a lerem e a escreverem num ritmo intenso e acelerado, como também incentiva a circulação de leituras e escritas por intermédio da conexão em redes abertas, como ocorre nas redes sociais: Facebook, MySpace, Orkut, NING, Twitter.

Para os jovens, o problema do acesso à leitura e à informação poderia ser superado com a criação de um equipamento cultural:

Na verdade o que sempre achei que fez falta, acho que não sei se só no Rio Grande do Sul, no Brasil, foi uma biblioteca pública, que faz muita falta, entendeu. Eu sempre pensei, bah, oh mãe, quando eu era pequeno e olhava os filmes americanos, mãe, a gente tem que ir na biblioteca, mãe, é temo que ir na biblioteca e depois descobri que não tem, entendeu. (I., 18 anos).

Mas o espaço precisa atender os seus desejos e necessidades, como se observa a seguir:

\begin{abstract}
Bibliotecas mais perto, né, porque, eu pegava na da ULBRA, só na da ULBRA que eu pegava livro emprestado mesmo, tipo, fazia a associação e tudo mais lá, só lá que eu pegava, o resto eu comprava tudo, porque tipo dificilmente tu vai encontrar, é que tipo gibis e mangás tu não, não é muito de tu vê pra pegar assim, raramente na verdade nem tem como, acho, mas livros, por exemplo, o pessoal deixa de, por exemplo, assim, livros populares, vamos dizer assim, por exemplo Harry Potter e Crepúsculo tu não encontra nas bibliotecas, tu só encontra livros de estilos literários, de obras literárias, de autores famosos assim que envolvem toda a literatura do Brasil e autores internos, assim, vamos dizer assim.' (M., 18 anos).
\end{abstract}

Fica-nos evidente que, por inúmeros motivos, o acesso à leitura e à informação é dificultado em seus cotidianos, tais como: ausência de bibliotecas públicas e/ou comunitárias; equipamentos e espaços culturais públicos inadequados, ou por demais suntuosos, em relação à realidade social em que estes jovens estão inseridos ou com acervo desinteressante e desadaptado aos seus interesses, bibliotecas distantes de seu local de moradia, tornando o acesso caro, alto custo para a aquisição de livros, entre outros.

R. Inter. Interdisc. INTERthesis, Florianópolis, v.13, n.3, p.81-100 Set.-Dez. 2016 


\section{CONSIDERAÇÕES FINAIS}

Discute-se, tanto no cotidiano, quanto nas rodas acadêmicas, sobre o fato de que, cada vez mais, os jovens não leem e não se interessam pela leitura. Há de se problematizar tal afirmação para que possamos compreender o que vem acontecendo com o chamado incentivo à leitura que muitos educadores procuram desenvolver em suas práticas profissionais. Pelo que vimos ao longo deste trabalho, os jovens, e possivelmente não somente eles, relacionam a leitura com livro impresso, com compromisso e com escola. Poucos reconhecem a leitura em outros suportes como algo legítimo. Tal prática também está associada a um certo "sofrimento", como se leitura não pudesse envolver prazer, afinal é obrigação.

Os jovens que acessamos para realizar este estudo não apenas leem nos seus cotidianos, mas também escrevem sobre eles. Leitura e escrita são possibilidades para conhecer e interagir com novas culturas, bem como formas de terapia utilizadas para dar conta da realidade. Chama a atenção o fato de que as produções daí provenientes são na maioria das vezes descartadas, pois já são concebidas na esteira da depreciação, tal qual a visão do tipo de leitura que por eles é feita. "A leitura e a escrita é, independente de seus suportes, um dos alicerces da geração de jovens da atualidade" (CARVALHO, 2012, p. 189). As novas tecnologias, neste sentido, mais aproximaram os jovens da leitura do que afastaram. É preciso quebrar, portanto, com a ideia de que existe um suporte ou tipo de leitura ideal ou superior a outras e valorizar as múltiplas formas de se relacionar com a informação de modo geral. De modo semelhante, Dumont (2002, p. 1) relata que há uma inversão de valores na forma como se avalia a leitura, pois "[...] analisa-se o texto, como arte ou não, relegando a segundo plano o objetivo primeiro: ser lido por alguém, ou o leitor."

Concluímos, portanto, que o não acesso à informação e à leitura está relacionada muito mais pela falta de oportunidades concretas do que pelo desinteresse de tais jovens por esta prática cultural. Tais dados se contrapõem a antigos estigmas de que as pessoas em situação de pobreza socioeconômica não teriam interesse pela leitura e pela informação ou se tivessem seria com qualidade inferior das demais. Além disso, rompe-se com a ideia de que a juventude em geral não se interessa por este tema. Considerando tais afirmações, precisamos repensar como oferecer o acesso à livros e informações para os jovens. Milanesi (1986), 
neste sentido, destaca que o importante na informação e nas bibliotecas, por exemplo, é a transformação das ideias, os conflitos que poderão trazer e a valorização da organização de acervos. Numa biblioteca, portanto, deverá existir a organização de acervos para desordenar as ideias. Facilitar o acesso à leitura é comprometer-se com a disseminação de novos paradigmas em relação à cultura e à educação. É empreender visões e compreensões críticas da realidade contribuindo, assim, para o exercício da cidadania.

R. Inter. Interdisc. INTERthesis, Florianópolis, v.13, n.3, p.81-100 Set.-Dez. 2016 


\title{
FREEDOM FOR MANGAS: YOUTH, READING, AND INFORMATION
}

\begin{abstract}
:
The present paper is an attempt to reflect and discuss the meaning and significance that youngsters from an outskirt district attribute to information and reading. 8 semistructured interviews were conducted with young adults between 18 and 24 years of age who took part on a social project called Casa das Juventudes (House of the Youth) in the Guajuviras suburb in Canoas, Brazil. Casa das Juventudes is a part of the 'Territórios da Paz' (Land of Peace) project and is a development and learning center as well as a leisure space. It houses PROTEJO, a social project that focus on youngsters who are subject to violence and other forms of social vulnerability. Our outcomes indicate that reading is part of their daily activities since the results of the interviews demonstrate that they express interest not only in literature but also in obtaining information both in and outside Casa das Juventudes. However, access to information is hindered for various reasons such as the absence of public libraries and cultural spaces suitable to their social reality. Access to information seems to be impeded not by lack of interest in reading but because of the inadequacy of books and by the high price of material acquisition.
\end{abstract}

Keywords: Reading. Youth. Cultural Tools. Library.

\section{LIBEREN LOS MANGAS: JUVENTUDES FRENTE A LA LECTURA Y A LA INFORMACIÓN}

\section{Resumen:}

En el presente artículo, buscamos reflexionar y discutir los sentidos y significados que los jóvenes de un barrio de la periferia poseen acerca de la lectura e información. Para esto, realizamos ocho entrevistas semi-estructuradas con jóvenes entre 18 y 24 años participantes de un proyecto social, llamado Casa de las Juventudes, en el Barrio Guajuviras, de Canoas/RS, Brasil, integrante del Proyecto Territorios de Paz. La Casa de las Juventudes es un centro de formación y espacio de convivencia. En ella funciona el PROTEJO (Protección de Jóvenes en Territorio Vulnerable), proyecto social volcado para los jóvenes en situación de violencia y otras formas de vulnerabilidad social. Los resultados indican que la lectura hace parte de la vida cotidiana de los jóvenes, una vez que los mismos expresan interés e iniciativa en tener contacto, dentro y fuera de la Casa de las Juventudes, con libros e informaciones en general. Con todo, el acceso a la lectura es dificultado en lo cotidiano por varios motivos, tales como: ausencia de bibliotecas públicas; equipamientos y espacios culturales públicos inadecuados, o por demás suntuosos, en relación a la realidad social en la que estos jóvenes están insertados. El no acceso a la información se configura más por la falta de acervo adecuado en las bibliotecas, asociado al alto costo para la adquisición de libros y otros documentos, que la falta de interés por la práctica de la lectura.

Palabras-clave: Lectura. Juventud. Equipamiento cultural. Biblioteca. 


\section{REFERÊNCIAS}

AREIAS, Déborah de $P$. Leitura e juventude: o que temos diante dos olhos? In: SEMANA DE EDUCAÇÃO (13. :Rio de Janeiro : 2008) Educação, formação e sociedade: desafios contemporâneos; comunicações e Pôsteres. Rio de Janeiro: UERJ, 2008.

BAUMAN, Zygmunt. Vida líquida. Rio de Janeiro: Zahar, 2007.

BRENNER, Ana Karina; DAYRELL, Juarez; CARRANO, Paulo. Culturas do lazer e do tempo livre dos jovens brasileiros. In: ABRAMO, Helena Wendel; BRANCO, Pedro Paulo Martoni. Retratos da juventude brasileira. São Paulo: Fundação Perseu Abramo, 2005. p. 175-214.

CALDIN, Clarice Fortkamp. A leitura como função terapêutica. Bibli: Revista de Bibliotecononomia e Ciência da Informação, Florianópolis, v. 6, n.12, dez. 2001.

CARVALHO, Larissa Camacho. Práticas de leitura e escrita na contemporaneidade: jovens \& fanfictions. Porto Alegre: 2012. Tese (doutorado) Universidade Federal do Rio Grande do Sul. Programa de Pós-graduação em Educação, 2012.

CASTRO, Mary Garcia; ABRAMOVAY, Miriam. Jovens em situação de pobreza, vulnerabilidades sociais e violências. Cadernos de Pesquisa, São Paulo, n. 116, p. 143-176, 2002.

CATANI, Afrânio Mendes; GILIOLI, Renato de Sousa Porto. Diversidade de interpretações das culturas juvenis. In: olhares. São Paulo : UNESP, 2008. p. 89-103. Culturas juvenis: múltiplos

DAYRELL, Juarez. O jovem como sujeito social. Revista Brasileira de Educação, n. 24, set./dez. 2003.

DAYRELL, Juarez. A música entra em cena: o rap e o funk na socialização da juventude em Belo Horizonte. São Paulo : USP, 2001. Tese (doutorado) Universidade de São Paulo. Programa de Pós-Graduação da Faculdade de Educação, 2001.

DUMONT, Ligia Maria Moreira. Reflexões sobre o gosto na escolha da leitura de lazer: desfazendo preconceitos. Ciberlegenda, Niterói, n.10, p. 1-10, 2002. 
DUPAS, Gilberto. O mito do progresso. Novos Estudos CEBRAP, n. 77, p. 73-89, mar. 2007.

FERREIRA, Sandra Patrícia Ataíde; DIAS, Maria da Graça Bompastor Borges. A leitura, a produção de sentidos e o processo inferencial. Psicologia em Estudo, Maringá, v. 9, n. 3, p. 439-448, set./dez. 2004.

GALVÃO, Tatiana Verônica Bezerra O papel das transformações sociais e da identidade juvenil na construção de comunidades de sentido. In: ENCONTRO DE ESTUDOS MULTIDISCIPLINARES EM CULTURA (4. : Salvador: 2008) Anais. Salvador : UFBa, 2008. Disponível em: http://www.cult.ufba.br/enecult2008/14338.pdf. Acesso em: 21 abr 2013.

GOULEMOT, Jean Marie. Da leitura como produção de sentidos. In: CHARTIER, Roger (Org.). Práticas de leitura. São Paulo : Estação Liberdade, 1996. p. 107-116.

INSTITUTO PRÓ-LIVRO. Retratos da leitura no Brasil. Rio de Janeiro : IPL, 2011. $129 \mathrm{f}$.

LOURENÇO, André Luiz Correia. Otakus: jovens brasileiros e cultura pop nipônica. In: Juventude contemporânea: culturas, gostos e carreiras. Rio de Janeiro: 7 Letras, 2010. p. 61-74.

MARINA, José Antonio; VÁLGOMA, María de la. A magia de ler. Lisboa, Ambar, 2007.

MILANESI, Luiz. Ordenar para desordenar: centros de cultura e bibliotecas públicas. São Paulo: Brasiliense, 1986. 261 p.

MINAYO, Maria Cecília de Souza. O desafio do conhecimento: pesquisa qualitativa em saúde. São Paulo: Hucitec, 2007.

MINAYO, Maria Cecília de Souza, (org.) Pesquisa social: teoria, método e criatividade. 28.ed. Petrópolis: Vozes, 2011.

OSWALD, Maria Luiza; ROCHA, Sergio Luiz Alves da. Sobre juventude e leitura na "idade mídia": implicações para políticas e práticas curriculares. Educar em revista, Curitiba, n. 47, p. 267-283, mar. 2013. Disponível em:

http://www.scielo.br/pdf/er/n47/14.pdf. Acesso em: 13 maio 2013. 
PLANO NACIONAL DO LIVRO E LEITURA. O que é o PNLL? In: Plano Nacional do Livro e Leitura. Brasília: PNLL, 2011. p.1.

PRIMEIRO Censo Nacional das Bibliotecas Públicas Municipais. In: BRASIL. MINISTÉRIO DA CULTURA. [Site oficial]. Brasília : MinC, 2011. Disponível em: http://www.cultura.gov.br/site/2010/04/30/primeiro-censo-nacional-das-bibliotecaspublicas-municipais. Acesso em: 12 nov. 2011.

SANTOS, Cíntia Sacramento do Espírito; DE MARCO, Giovanna. O Jovem e a construção de "si" através da publicização de imagens e postagens nas redes sociais. In: SIMPÓSIO EM TECNOLOGIAS DIGITAIS E SOCIABILIDADE (Salvador : 2012). Anais. Salvador, 2012. Disponível em: http://gitsufba.net/anais/wpcontent/uploads/2013/09/n1 jovem 44921.pdf. Acesso em: 13 mar 2013.

SPOSITO, Marilia Pontes. Juventude: crise, identidade e escola. In: DAYRELL, Juarez, org. Múltiplos olhares sobre educação e cultura. Belo Horizonte: Ed. UFMG, 2006. p. 96-104.

UNESCO. Acesso à Cultura no Brasil. Brasília : 2011. Disponível em: http://www.unesco.org/new/pt/brasilia/culture/culture-and-development/access-toculture/. Acesso em 31 out 2011.

UNESCO. Políticas públicas de/para/com as juventudes. Brasília: UNESCO, 2004. 304 p. Disponível em:

http://unesdoc.unesco.org/images/0013/001359/135923por.pdf. Acesso em: 14 abr 2012.

VELHO, Gilberto; DUARTE, Luiz Fernando Dias (orgs.). Apresentação. In: Juventude contemporânea: culturas, gostos e carreiras. Rio de Janeiro: 7 Letras, 2010. p. 7-8.

\section{Artigo}

Recebido em 02 de Março de 2016

Aceito em 11 de Julho de 2016 